\title{
Chemical weathering of a granitic watershed: coupling Lithium isotopes and reactive transport modeling, preliminary results
}

\author{
Romain Millot ${ }^{1, *}$, Joachim Tremosa ${ }^{1}$, and Philippe Négrel $^{1}$ \\ ${ }^{1}$ BRGM - French Geological Survey, F-45060 Orléans, France
}

\begin{abstract}
In the present study, we report lithium concentrations and $\mathrm{Li}$ isotopic compositions for different samples within a granitic watershed (Margeride, France). We investigate unweathered bedrock and samples displaying different stages of weathering in order to characterize $\mathrm{Li}$ isotopic fractionation. This was achieved by coupling lithium isotope geochemistry and reactive transport modeling during granite weathering at the scale of this watershed. The following manuscript reports methodology and the preliminary data.
\end{abstract}

\section{Introduction and objective of the study}

Assessing the behaviour of lithium and the distribution of $\mathrm{Li}$ isotopes during weathering is of major importance for studying water/rock interactions at the surface of the Earth. This is because lithium ( ${ }^{6} \mathrm{Li} \sim 7.5 \%$ and ${ }^{7} \mathrm{Li} \sim 92.5 \%$ ) is a fluid-mobile element and, due to the large relative mass difference between its two stable isotopes, is subject to significant low temperature mass fractionation which provides key information on the nature of weathering processes.

Recent studies have shown that the range of $\delta^{7} \mathrm{Li}$ values span more than $50 \%$ at the Earth surface $\left(\delta^{7} \mathrm{Li}=\left[\left({ }^{7} \mathrm{Li} /{ }^{6} \mathrm{Li}\right)_{\text {sample }} /\left({ }^{7} \mathrm{Li} /{ }^{6} \mathrm{Li}\right)_{\mathrm{L}-\text { SVEC }}-1\right] \times 10^{3}\right)$. Lithium isotopes are thought to be strongly affected by isotope fractionation associated with secondary mineral formation during silicate weathering [1-9].

To date, both the magnitude of the Li isotopic fractionation associated with water-rock interaction and the factors controlling these fractionations, are poorly understood. However, both field and experimental studies have shown that ${ }^{6} \mathrm{Li}$ is preferentially retained by secondary minerals during silicate weathering. Accordingly, the fractionation of $\mathrm{Li}$ isotopes is dependent upon the extent of chemical weathering. Large fractionation seems to occur during early stage of weathering, while little fractionation is observed during more intense or prolonged weathering in stable environments.

In this context, we investigate the granite Margeride massif to attempt to distinguish the dominant processes controlling $\mathrm{Li}$ isotope fractionation over the watershed.

\footnotetext{
*Corresponding author: r.millot@brgm.fr
} 


\section{Materials and methods}

The granite-gneiss Margeride massif is located in the French Massif Central (Fig. 1). A range of solid samples were selected to represent the granite weathering process, starting from a fresh granite sample in near surface conditions and in two sites on the catchment. We also selected samples at various stages of weathering, from the surface saprolite taken from sediments collected on riverbanks and from fields bordering the streams.
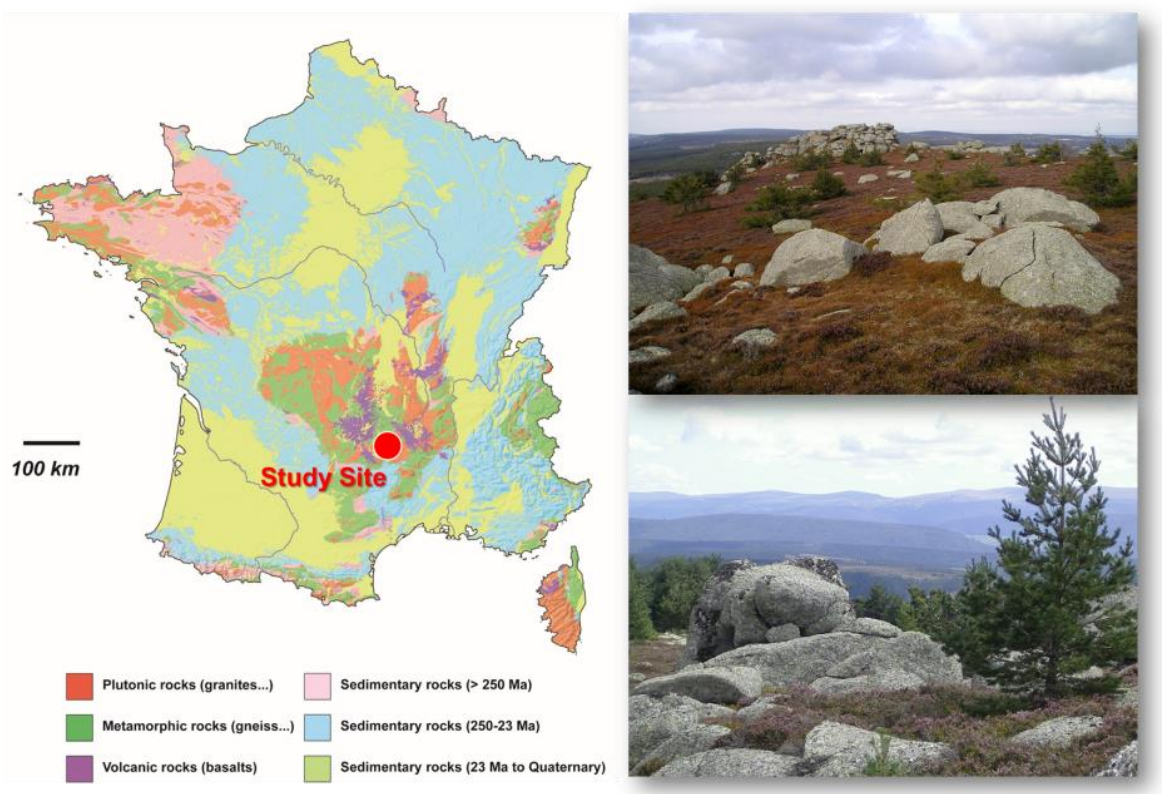

Fig. 1. Location of the study site in France and pictures of granite-gneiss Margeride massif located in the French Massif Central.

Lithium isotopic compositions were measured using a Neptune ${ }^{+}$Multi-Collector ICPMS [10]. ${ }^{7} \mathrm{Li} /{ }^{6} \mathrm{Li}$ ratios were normalized to the L-SVEC standard solution (NIST SRM 8545 [11]) following the standard-sample bracketing method. Typical in-run precision on the determination of $\delta^{7} \mathrm{Li}$ is about $0.1-0.2 \%$ o $\left(2 \sigma_{\mathrm{m}}\right.$, standard error of the mean).

Chemical separation of $\mathrm{Li}$ from the matrix was achieved before isotope analyses, following a procedure that uses a cationic exchange resin (a single column filled with $3 \mathrm{~mL}$ of BioRad $\mathrm{AG}^{\odot} 50 \mathrm{~W}-\mathrm{X} 12$ resin, 200-400 mesh) and $\mathrm{HCl}$ acid media $(0.2 \mathrm{~N})$ for $30 \mathrm{ng}$ of Li. Blanks for the total chemical extraction were less than $30 \mathrm{pg}$ of $\mathrm{Li}$, which is negligible since this represents a blank/sample ratio of $<10^{-3}$.

\section{Coupling $\mathrm{Li}$ isotope geochemistry and reactive transport modeling}

One of the major obstacles to using $\mathrm{Li}$ isotopes is the ability to obtain a clear distinction between primary effects associated with source/origin and the effects of secondary processes that can modify the isotopic signature (e.g., mineral alteration, dissolution, precipitation).

We have recently tested a steady state weathering model with a Rayleigh type fractionation in the Margeride granite [12], but subsurface systems are very complex and involve not only transport of solutes, but also many concurrent heterogeneous and 
homogeneous reactions that must be accounted for (dissolution/precipitation and adsorption/desorption are key reactions for lithium that can fractionate $\mathrm{Li}$ isotopes). Understanding and interpreting the isotopic signatures requires accounting for all these processes, which can only be done using computer simulations, called 'Reactive Transport Models' (RTMs), that can solve the governing equations for solute transport and geochemical transformations simultaneously.

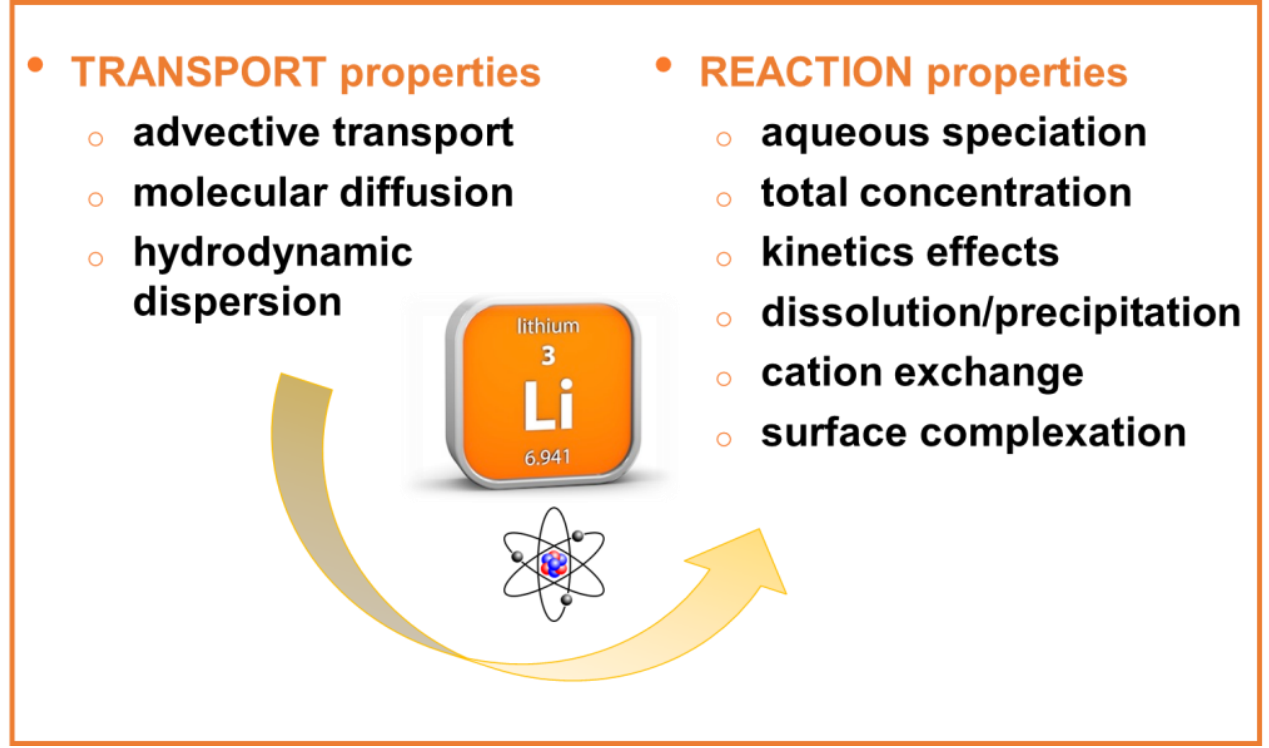

Fig. 2. Schematic diagram showing the coupling between transport and reaction properties with the implementation of $\mathrm{Li}$ isotope fractionation.

During water/rock interaction, one must implicitly or explicitly make assumptions of the state of equilibrium between the fluid and the rock. Early models were fundamentally static rather than dynamic in nature, however in the Earth Sciences the driving force for most reactions is transport. So, the main challenge is to couple reactive transport basics that combine the transport processes with expressions for geochemical reactions and system properties (hydraulic conductivity, porosity, tortuosity) in both space and time. Isotopic variations can provide an additional tracer of reaction pathways within such ambiguous reaction networks.

\section{First conclusion and future direction}

The first stages of this work were intended to building a robust alteration model considering the initial minerals within the bedrock (wt.\% and Li concentration). This weathering model was developed using the PHREEQ-C code [13] and simulates a weathering sequence in agreement with the products observed within the soils, saprolites and sediments for Li concentrations. This first stage was important in order to conserve the mass balance for lithium. The next step, we are working on now, is to implement Lithium isotope fractionation during weathering reactions. This model for coupled chemical and isotopic equilibration [14-16] explicitly considers isotopic equilibration in the absence of bulk chemical disequilibrium by making use of a solid-solution model for the precipitating mineral phase (no isotopic fractionation is likely to occur during mineral dissolution). 
With this innovative approach it is very likely that quantitative interpretation of isotope data will take a decisive step towards the full integration of isotope species into reactive transport models in agreement with previous studies [14-16].

We would like to acknowledge K. Maher and M. Winnick from Stanford University for fruitful discussions. The Research Division of BRGM is acknowledged for funding. RM is particularly grateful to T.D. Bullen for helping him in the first stages of Li isotopes implementation at BRGM more than 15 years ago; this work is dedicated to his memory.

\section{References}

1. J.S. Pistiner, G.M. Henderson, Earth and Plan. Sci. Lett. 214, 327-339 (2003)

2. R.L. Rudnick, P.B. Tomascak, H.B. Njo, L. Robert Gardner, Chem. Geol. 212, 45-57 (2004)

3. B. Kisakürek, M. Widdowson, R.H. James, Chem. Geol. 212, 27-44 (2004)

4. B. Kisakürek, R.H. James, N.B.W. Harris, Earth and Plan. Sci. Lett. 237, 387-401 (2005)

5. Y. Huh, L.C. Chan, O.A. Chadwick, Geochem. Geophy. Geosys. 5, 1-22 (2004)

6. E.C. Hathorne, R.H. James, Earth and Plan. Sci. Lett. 246, 393-406 (2006)

7. P.A.E. Pogge von Strandman, K.W. Burton, R.H. James, P. van Calsteren P., S.R. Gislason, F. Mokadem, Earth and Plan. Sci. Lett. 251, 134-147 (2006)

8. N. Vigier, S.R. Gislason, K.W. Burton, R. Millot, F. Mokadem, Earth and Plan. Sci. Lett. 287, 434-441 (2009)

9. R. Millot, N. Vigier, J. Gaillardet, Geochim. et Cosmochim. Acta 74, 3897-3912 (2010)

10. R. Millot, C. Guerrot, N. Vigier, Geost. and Geoana. Res. 28, 53-159 (2004)

11. G.D. Flesch, A.R. Anderson, H.J. Svev, Internat. J. of Mass Spectro. and Ion Phys. 12 , 265-272 (1973)

12. Ph. Négrel, R. Millot, (In Prep.)

13. D.L. Parkhurst, C.A.J. Appelo, User's guide to PHREEQC (Version 2) (1999)

14. C.I. Steefel, K. Maher, Rev. in Mineral. \& Geochem. 485-532 (2009)

15. C.I. Steefel C.I., J.L. Druhan, K. Maher, Proc. Earth and Planet. Sci. 10, 208-217 (2014)

16. J.L. Druhan, K. Maher, Water Res. Res. 53 (2017) 